Fecha de recepción: octubre 2019 Fecha de aceptación: diciembre 2019 Versión final: noviembre 2021

\section{Prolijidad y corrección. Vectores de normalización y socialización interclase para el cuidado del cliente de elite en una marca comercial porteña de lujo tradicional}

\begin{abstract}
Resumen: Este ensayo se propone indagar los vectores de normalización circulantes para el cuidado del cliente de elite. Para ello, se evaluará la incidencia de la apariencia vestimenta, apariencia física y modos de proceder en la empleabilidad en el segmento de compra-venta de lujo tradicional a partir del estudio de una histórica y prestigiosa casa de marroquinería, indumentaria y talabartería en la Ciudad de Buenos Aires, vinculada a la elite terrateniente argentina y a la aristocracia internacional. Analizaremos las lógicas de socialización interclase, y cómo su internalización -o no- por parte de personas provenientes de sectores medios y/o populares puede devenir en su potencial acceso al trabajo en el sector de venta de productos de lujo.
\end{abstract}

Palabras clave: lujo tradicional - empleabilidad - normalización de la apariencia - marcas comerciales - compra-venta - moda - sectores medios y populares - clientes de elite - Argentina.

[Resúmenes en inglés y portugués en las páginas 136-137]

${ }^{*}$ Diseñadora de Indumentaria, Universidad de Buenos Aires. Candidata Doctoral en Antropología Social, Instituto de Altos Estudios Sociales, Universidad Nacional de San Martín. Maestranda en Ciencias Sociales y Humanidades mención Historia, Universidad Nacional de Quilmes.

\title{
Introducción
}

Este ensayo surge a partir del análisis de una marca tradicional de lujo porteño, aunque sus intenciones van más allá del caso empírico. Las reflexiones que ocupan estas líneas pretenden hablar en un sentido amplio de lógicas de movilidad social, de socialización interclase y de normativización de la apariencia e interacciones compra-venta para el cuidado del cliente de elite.

Como se verá en las páginas subsiguientes, los modos de relación entre dueños, vendedores y clientes nos permitirá abordar el estudio de las interacciones interclase como ámbi- 
to de socialización mimética en dirección de abajo hacia arriba. En estas circunstancias, exploraremos si el acceso al empleo en el caso observado es la resultante de la aceptación implícita de una no igualdad entre vendedor y cliente, es decir, de una reproducción de las asimetrías.

Asimismo, indagaremos sobre los vectores de normalización circulantes en este tipo de ámbitos, los modos de proceder apropiados y la apariencia requerida para el desempeño del puesto de vendedor, y cómo se movilizan ciertos imaginarios en la apuesta interactiva de compra-venta, intentando desentrañar lo sociohistóricamente sedimentado.

Por último, consideramos un dato valioso a explorar que la existencia de este tipo de marcas sea mayormente perceptible para el segmento al cual se dirige, pudiendo aparecer invisible a ojos de un estrato inferior, lo que refuerza la noción de hermetismo y endogamia al interior del segmento de elite tradicional, ricos estructurales, frente a otras trayectorias de enriquecimiento de tono meritocrático ligados al lujo ostensible y el consumo de marcas mundialmente famosas.

La comunicación y la divulgación de la marca, como veremos, también adquiere un cariz especial, donde la publicidad se efectúa por referidos mediante el boca a boca, a través de redes de confianza que garantizan un consumo adecuado a su posición social.

\section{Una marca comercial porteña en el segmento del lujo tradicional. La reconstrucción de la estructura social argentina a través de una historia de elites terratenientes, inmigración y movilización ascendente (1868-2014)}

En el 2006 yo era una joven de 25 años, segunda generación argentina de inmigrantes italianos. Pertenecía a una de esas familias que gracias al trabajo y el estudio en la universidad pública había logrado la movilización ascendente hasta posicionarse socialmente en el segmento medio, con una niñez y adolescencia sin privaciones en un barrio del primer cordón del conurbano. Por esos años estaba tratando de abrirme camino como diseñadora de indumentaria buscando empleo en el ámbito privado, luego de una breve experiencia como copropietaria de un negocio en el cual comercializaba mi propia marca de diseño independiente. En el 2006, y por primera vez desde su fundación, una prestigiosa casa de marroquinería, indumentaria y talabartería necesitaba cubrir el puesto de diseñadora, trabajo al que postulé y gracias al cual ingresé a un mundo que desconocía. Se trataba de una marca con casi 150 años de trayectoria atendiendo al segmento de elite tradicional local y a clientes de la aristocracia internacional, con presencia en el corredor norte de la Ciudad de Buenos Aires y prestigio mundial, pero en mis 25 años de vida, y a punto de recibirme de Diseñadora de Indumentaria en una universidad pública, esta empresa había sido invisible a mis ojos. Sabrá disculpar el lector la realización de esta pequeña autobiografía para dar cuenta de un dato no menor, mi avenimiento desde el sector medio y popular me ocasionaba una ceguera de clase, este filtro era reflejo de las diferencias entre consumos y estrategias comunicacionales de lujo ostensible y lujo tradicional, y el hermetismo de los circuitos en los que circulan las elites tradicionales porteñas y las elites nobiliarias del escenario mundial. Excede a este artículo ampliar qué sucedió luego de mi reclutamiento, 
sólo diré que trabajé allí unos dos años, y retomé el contacto casi siete años después, en el marco de mi investigación de doctorado en antropología social, para entrevistar a quien en otros tiempos fuese mi empleadora, la heredera y dueña de la firma.

Hasta aquí llegan los antecedentes autobiográficos del material empírico que será indagado con la bibliografía propuesta, datos en los que buscaré encontrar algunos lineamientos sobre los vectores de normalización y socialización interclase en las interacciones de compra-venta en el segmento de lujo tradicional porteño.

\section{Trayectoria, mérito y reconocimiento. El posicionamiento de una marca en el segmento de lujo tradicional porteño}

Ya desde el XIX existía cierto consenso en identificar a las clases altas tradicionales con los grandes terratenientes de la pampa y las actividades de agroexportación, asentadas en la ciudad de Buenos Aires sus principales ingresos provenían, no obstante, del campo. Los miembros de las familias patricias, la alta sociedad de Buenos Aires, la generación del ochenta, los grandes hombres del orden conservador parecieron términos transparentes y homologables (Heredia, 2013b, p. 46).

Parecía evidente que una elite de notables habría acumulado y controlado, hasta las primeras décadas del siglo, los principales resortes del poder económico y político del país. Hablamos de unas pocas familias con apellidos notables en las que confluía el poder económico y eran capaces de "erigir sus pautas de honor, sociabilidad, consumo como patrones de identificación y formateo del resto de la sociedad" (Ibid). La fuente del enriquecimiento fue mutando, y hacia las primeras décadas del siglo XX el campo fue desplazado como principal ingreso, en su lugar emergía una clase alta urbana ligada a la industrialización y muy frecuentemente integrada por inmigrantes que habían logrado prosperar. En este sentido, la reposición de la historia de la firma recoge la capacidad de movilización social de la Argentina de entresiglos. En 1868 cuando la marca comenzó no tenía el nombre actual, y estaba dedicada casi exclusivamente a la producción de artículos de viaje y pecheras y monturas para caballos.

Los abuelos de la actual dueña, inmigrantes españoles, llegaron a la Argentina hacia el año 1900. Siendo artesanos en su tierra de origen, comenzaron a ejercer su oficio en los talleres de la firma y, llegado el momento, llevaron a su propio hijo a trabajar con ellos. En el año 1939 la familia fundadora de la marca decidió cerrar y ocuparse de otras cosas, situación que derivó en un acuerdo con el padre de la dueña actual para que este les comprase la empresa. En el año 1941 le cambian el nombre por el que permanece hasta nuestros días. Retomemos por un momento las palabras de la dueña, recogidas en nuestra entrevista:

Mi padre de ser empleado pasa a ser el dueño de la empresa. El fuerte de la casa eran los equipajes los baúles toda la parte de campo y todo lo de caballos, pero no caballo de deporte sino caballo para moverse, toda la vida era a caballo, eso y los viajes, viajes en barco. En esa época eran carruajes para campo, para trabajar, deportes no. Los estancieros todos los meses te compraban pecheras, 
todo eso cambió, ahora tienen camionetas $4 \times 4$. Después se pasó de los baúles a las valijas, pero las valijas con armazón de madera, para los viajes en barco se utilizaban las valijas armadas, estilo Vuitton que se sigue viendo. Nosotros éramos proveedores de varios ejércitos, el Ejército de Chile, el Ejército de Uruguay, de México, fuimos proveedores de varios ejércitos. Luego la cosa fue cambiando. La parte de talabartería quedó reducida a lo que es deporte, para campo sólo muy de vez en cuando (Rossi \& Caruso, M.I., 2014).

Como se puede apreciar en el relato, estamos ante la familiar historia del inmigrante que llega a Argentina sólo con su oficio, y va logrando escalar su posición social y económica a través de su trabajo. Estos inmigrantes que se hicieron desde abajo representan otro tipo de riqueza, la no heredada, la meritocrática, asociada al esfuerzo, a la especialización y al hombre que se hace a sí mismo (Heredia, 2011, p. 79-80).

Para Pareto (2013) el hecho de que la aristocracia porteña experimente una retirada del ámbito público a partir del siglo XX, y la invisibilidad, el ocultamiento y el hermetismo pasen a ser sus principales características, no implicó una pérdida de poder (Heredia, 2013 b, p. 47). Este retroceso no fue otra cosa que la respuesta al avance de los nuevos ricos, y un intento de diferenciarse en sus modos de actuar. La metáfora entre establecidos y outsiders (Elías y Scotson, 2000) nos parece útil para plantear la diferenciación entre elite tradicional y recién llegados, una marcación que se maneja en el terreno de las percepciones, que va más allá de lo cuantitativamente medible, y donde la Encuesta Permanente de Hogares o el GINI poco pueden hacer para delimitarla (Benza y Heredia, 2012, p. 5). Entonces, ¿Como definir a los de arriba?, ¿cómo diferenciar elites tradicionales de nuevos ricos? Benza y Heredia (Ibid, p. 6) establecen ciertos diacríticos que serían característicos de las elites, tales como la pertenencia a familias de origen patricio, la posesión de los medios de producción o la autoridad en el proceso productivo, y la acumulación patrimonial. Precisamente, esta distinción se basa en los efectos morales de un nosotros con una jerarquía simbólica superior en tanto descendientes de familias tradicionales, y aunque con débil injerencia en la esfera de poder político se perciben, parafraseando a Elías, seres social y moralmente superiores, legitimando su superioridad en el principio de antigüedad. El efecto moral aparece como garantía de reproducción simbólica del prestigio y la tradición. Es así como surgen alianzas tales como la celebrada entre la marca en cuestión y la bichozna de uno de los célebres próceres de la independencia, compartiendo con su ancestro no sólo la consanguinidad sino también reforzando el vínculo mediante la portación del notable apellido. Como explica Tilly (2002) la reproducción en el tiempo de las diferencias en el bienestar y las oportunidades de vida está relacionada con modelos relacionales de la vida social, elementos que aparecen vinculados por su continuidad semántico, sociohistóricamente sedimentada en la movilización de un mismo imaginario, más que con diferencias individuales en términos meritocráticos (Heredia, 2013).

"Los herederos de las familias patricias sufrieron una fragmentación de su fortuna en las sucesivas generaciones y si bien no pudieron acceder al poder político luego del retorno a la democracia" (Heredia, 2011, p. 48), con trayectorias que suelen ser invisibles a los sectores medios y populares lograron moverse convenientemente al interior de sus murallas 
simbólicas, creando estrategias que favorecen los lazos entre iguales tendiendo a reproducir la elite tradicional como elite moral antes que como elite económica.

Geográficamente, no es casual el asentamiento de la marca en el corredor norte de la ciudad. Frecuentemente documentada, la aversión de las elites locales a la masiva inmigración que llegó entre el siglo XIX y principios del XX produjo su desplazamiento hacia el norte. Como aparece en Heredia (2011) ya Imaz en los años 60 hablaba de una concentración de familias patricias en Retiro y Recoleta, cuestión ampliamente reconocida por los operadores inmobiliarios que asocian el barrio al nivel sociocultural de las familias tradicionales. Resulta interesante analizar las fronteras entre el grupo de artículos que pueden ser agrupados en el segmento de lujo tradicional y aquellos que podrían ubicarse bajo la denominación de lujo ostentoso. Creemos que esta distinción comparte cierta afinidad con la diferenciación explorada por Heredia (2011) entre ricos estructurales y nuevos ricos, encontrando en sus respectivas huestes potenciales consumidores de estos segmentos del mercado del lujo. Como explica la socióloga, la figura del aristócrata está ligada a la pertenencia a una familia, a una estirpe de alta alcurnia, en cambio, la figura del burgués propone cierta igualdad originaria donde el progreso individual se lograría en base al mérito personal. Estas dos actitudes se ven reflejadas asimismo en sus consumos, mientras los aristócratas reivindicarían el patrimonio heredado y apreciarían la sobriedad y la sutileza en las costumbres y la moda, los burgueses harían una oda a la meritocracia, y "encontrarían en la ostentación un modo de subrayar y hacer pública la recompensa obtenida" (Ibid, p. 80).

La dueña vivió esas transformaciones al experimentar un cambio en los consumos, que obligó a la casa a adaptarse e incorporar otros productos.

La casa tuvo que ir cambiando. En los años 50 era muy normal que las señoras cuando cumplían los 25 años de casados tuvieran su tapado de astracán, su collar de perlas y su cartera de cocodrilo, era un clásico, hoy se puede decir que todo lo que es exótico, pocas argentinas lo compran y lo consumen mucho los turistas. Hoy la argentina quiere que tenga el monograma y que todos sepan que valor tiene. La distinción no pasa por el material. Tenemos público local en algunas cosas, pero las cosas de valor el extranjero las reconoce más. La última línea que incorporamos fue el calzado, como teníamos las botas de montar, luego nos dio muy buen resultado y es un rubro que viene creciendo mucho. El extranjero viene mucho por el boca a boca (Rossi \& Caruso, M.I., 2014).

En los estudios de Heredia (2011) existe un consenso en que la riqueza cambió de manos hacia los años 70, cuando la democratización de la educación y la industrialización propiciaron el ascenso de nuevos grupos a la riqueza, pero la inexistencia de una reforma agraria ayudó a la perpetuación de las prerrogativas de las familias tradicionales y, por otro lado, fueron necesarios para el suministro de divisas en la compra de maquinaria industrial. Con la apertura a las importaciones aplicada por el modelo liberal de la última dictadura, estos cambios también afectaron los hábitos de consumo de lujo tradicional, como explica nuestra entrevistada: 
Hubo una época en donde la clientela, la aristocracia, tenía la costumbre de dejar sus tarjetas, y decían tengo un casamiento, envíen un juego de valijas, entonces era el típico regalo de casamiento. Hoy se volcaron a los electrodomésticos o a las listas de regalos donde ya no sabes ni lo que regalaste. Pero durante muchos años, con las familias tradicionales argentinas, teníamos cajas donde estaban todas las tarjetas y ahí teníamos los teléfonos y decían al Dr. Fulano envíenle un bolso, pero ni venían, ya confiaban en la casa, pero esas cosas hubo que ir reemplazándolas con otras cosas, otras actitudes, porque esas familias ya no compran. La venta local era mínima en comparación con lo que se exportaba, llegamos a exportar 1600 monturas por mes, dependiendo de si tenían mayor o menor de obra. Cuando vino la época de la tablita de Martinez de Hoz se hizo muy difícil sostener el mercado, empezamos manteniendo el precio y los americanos, que eran el principal mercado, ponían un catálogo por año y no lo podían cambiar y a nosotros ese dólar fijo nos fue consumiendo, se hizo cada vez más difícil mantener la continuidad. Entonces, hubo que reemplazarlo y dedicarse más a lo local, y ahí fue cuando incorporamos lo que es moda, porque fue la apertura de la importación, con lo cual se sustituía el regalo de casamiento con cualquier cosa que viniera de afuera, entonces hubo que reinventarlo y adaptarlo a todos los cambios (Rossi \& Caruso, M. I., 2014).

Aunque hacia 1970 la propiedad de la tierra seguía en manos argentinas, en los 20 años siguientes, y más específicamente hacia 1990 se produjo la llegada de grupos multinacionales y una consecuente extranjerización de la tierra, la industria y, en consecuencia, la riqueza. Es así como localmente la elite tradicional fue disminuyendo al ritmo que crecía una elite meritrocrática y corporativa. Según análisis recientes de Heredia (2012) la composición de la clase alta nacional es mayoritariamente asalariada, y el espacio económico excede las fronteras del país, observando una managerización del poder económico en detrimento del poder tradicional capitalista.

\section{Buscando burgueses hiper-correctos para la venta de lujo a aristócratas. Apariencia y modos normalizados para el acceso al empleo en el segmento de atención al cliente de elite}

En este apartado abordaremos los vectores de normalización de ciertos modos de proceder y apariencia deseables en el sector de venta para el contacto con clientes del segmento de lujo.

El análisis de Barber (1991) sobre el rol de la familia como socializador y en especial el apartado del trabajo como sociabilizador es fundamental para entender cierta incorporación, imitación y aprendizaje informal de la adecuación a la interacción con sectores de elite. Se habla entonces de un fenómeno de mímesis de abajo hacia arriba, donde las zonas de contacto interclase activan dispositivos pedagógicos de socialización de la persona de clase más baja en los modos de existencia de las personas de clase más alta a la cual prestan 
algún servicio, como dice Barber, son personas que pueden encontrar en el trabajo un medio de aprender a conducirse al estilo de las clases altas (Ibid, p. 295). En términos del autor, se trata de una re-socialización en la normatividad del estrato con el que se interactúa, siendo que, al tiempo, el trabajador incorpora estas normas sobre las buenas maneras, el gusto y los procederes como propias.

En el caso empírico que nos ocupa hemos podido observar que los vendedores reclutados pertenecen a diferentes sectores de la burguesía, por lo que podríamos abarcarlos de modo general en lo que llamaríamos clase media. Al pensar en la hiper-corrección y el control absoluto de la apariencia y los modales resulta interesante recurrir instrumentalmente a Bourdieu (1999), y su caracterización de la pequeña burguesía donde la hiper-identificación estaba dada por tratarse de recién llegados y encontrarse precisamente en una situación de no familiaridad. Del mismo modo, este autocontrol del empleado es complementado por una vigilancia extrema por parte del empleador, y la búsqueda de determinadas garantías de corrección y prolijidad en el trato y la apariencia, y templanza en el carácter para el cuidado del cliente de elite. En relación con ello, al consultar sobre el reclutamiento de personal a la actual dueña de la marca nos encontramos con el siguiente relato:

En lo que hace a criterios de selección mi padre era el más exigente, el procuraba que las mujeres tengan sus manos prolijas, que todos los días tenían que tener un paquete de pastillas de menta y usarlas porque si estaban hablando con un cliente bajo ningún concepto podían tener mal aliento, si hubiesen fumado o lo que fuese, se cuidaba muchísimo la presencia. (Nosotros) tratamos de seguir, damos uniforme, calzado, trajes a los hombres y mujeres e intentamos de que tengan un nivel de educación, y sobre todo una cosa que tratamos que no haya cambiado a lo largo de estos años es la calidad. Siempre el objetivo es la calidad en el producto y la calidad en la atención, el cliente tiene que tener una atención acorde al producto, es muy importante, la verdad que eso lo reconocen y lo agradecen, agradecen la atención de uno u otro vendedor. Tratamos de que cada cliente se sienta como único y atendido en lo que necesite, no se trata de una venta agresiva, es más un asesoramiento. Para el reclutamiento se tienen referencias para ver si más o menos corresponde al puesto y qué es lo que podemos esperar de esa persona, y tolerancia a la presión, porque a veces hay clientes que vienen por alguna situación ofuscados, y saber como relajarlos. Se les da una preparación, pero fundamentalmente lo que buscamos es qué es lo que trae esa persona de base (Rossi \& Caruso, M.I., 2014).

Podemos observar también como criterio de empleabilidad que el vendedor haya estado expuesto a un tipo de socialización, ya sea familiar o en el trabajo que esté en sintonía con el segmento del mercado al cual se atiende, de este modo es considerado como un capital extra la trayectoria del postulante que ha pasado por ámbitos ,no necesariamente de indumentaria, pero en los que se cuide al cliente, y es visto de forma negativa los modos asociados a la venta de ropa informal. Como se deja entrever en las siguientes líneas: 
Buscamos que el vendedor de la imagen de una persona prolija, correcta, no discriminamos nunca ni por edad, ni por sexo, pero si por supuesto que sea una persona que su aspecto sea prolijo, que sea correcta y que tenga buenos modales, después si la persona es grande o es joven no hay problema. He tenido excelentes vendedores que por ahí nunca habían estado en la venta, de hecho una vendedora que tuve muy buena venía de la gastronomía, era chef, y que realmente tenía mucho ángel para tratar con los clientes. Hay que ver si la persona tiene buena comunicación, eso te vas dando cuenta, no es necesario que tenga que venir de una marca. Lo que sí es notorio en los hombres, lo que nos ha dado buen resultado, son los hombres que vienen de sastrería, si son buenas sastrerías tienen una muy buena formación, que vienen de sastrería tradicional por ejemplo Hugo Boss, Giesso. En mujeres por ahí han venido de algún local en que se cuida al cliente. Por ahí si vienen de marcas informales (...) ni siquiera te preguntan qué querés. Nosotros, si es un extranjero, uno ya sabe las costumbres y te quedás un poco retirado por si necesita algo, no estar sobre el cliente pero que sepan que estás atento a cualquier cosa que necesiten (Rossi \& Caruso, M.I., 2014).

Como explica Bourdieu (1999) en el pequeño burgués coexiste la idea de hiper-corrección con la búsqueda de los modelos de autoridad, se extrema el cuidado y las maneras por miedo a no hacer lo suficiente, a perder la compostura. Podría aventurarse que en estas situaciones aumenta la presión sobre los vendedores, ya que la situación interactiva de compra-venta con clientes de elite exige un esfuerzo de autovigilancia constante, cuya relajación implicaría el riesgo de quedar fuera de lugar o parafraseando a Goffman (1970) de perder la cara.

Trazando un paralelo con el estudio de Barber (1991), sobre la socialización de los niños de la clase mercantil medieval, podríamos decir que una de las capacidades más valoradas en los vendedores del segmento de lujo tradicional sería el autodominio, un dominio que adquiere un carácter moral. Nuevamente nos encontramos con el autocontrol de las emociones, y no casualmente se trata de un tipo de socialización de tipo jerárquico, acorde a las lógicas de un mundo organizado en base a la autoridad como diría Barber. Por ello, podríamos decir que existe una relación directa entre la hipercorrección y la asimetría de la interacción, donde los vendedores de extracto burgués expresan en el tipo de trato jerarquizado propinado a sus clientes la reproducción de sus posiciones sociales.

En relación con la buena presencia Bourdieu (1991) plantea de qué manera en el juicio al gusto cada grupo se construye en base a una moral determinada, y es construido en relación a los gustos de otros, dominantes y dominados, la hipercorrección denotaría extrañamiento en la copresencia de un otro considerado superior en la escala social. Creemos que la repetición de palabras tales como corrección, cuidado, prolijidad son puntas de iceberg que requieren un análisis más profundo que retomaremos en estudios futuros. 


\section{El boca a boca, las redes de confianza y la recomendación. La clave secreta del acceso al consumo de elites}

Por último, abordaremos las formas de acceso al lujo tradicional y sus modos de comunicación mediante el boca a boca, las redes de confianza y recomendación. Como expone Filgueira (2001) existen ciertos activos sociales relativos a cada estrato, "la inserción en redes con elevado grado de capital social y la mayor disponibilidad de activos que circulan en las mismas, confianza, apoyo mutuo, información, influencia, mejoran las chances de desempeño de los individuos en el sistema de estratificación" (ibid., p. 21). La familia aparece como uno de los principales núcleos de capital social, pero otros círculos informales son igualmente importantes, las reuniones de trabajo, los eventos de protocolo, la pertenencia a clubes de elite, etc.

Como veremos a continuación, estamos ante la presencia de una marca que casi no publicita en los medios usuales como revistas, campañas fotográficas de difusión masiva, etc. sino que es el boca a boca el que atrae nuevos clientes. En esta línea argumentaba la dueña de la marca:

Nuestra marca está presente en muchos países. El sector de protocolo de presidencia cuando han sido elegidos papas, o en viajes presidenciales de distintos presidentes, llevaban regalos de aquí, no porque tuvieran un contacto en especial, sino porque ellos elegían llevar algo de acá.

Eso nos pasa también con las embajadas, no tenemos ningún contacto pero son ellos los que requieren, entonces un embajador le va recomendando a otro embajador. Han venido del Líbano, de Arabia, es que se recomiendan en reuniones y al otro y al otro, entonces empiezan a venir. Infinidad de clientes, las realezas de todos los países. La verdad es que somos muy flojos en la parte de comunicar, en ese sentido es más el boca a boca. (...) Uno va recomendando al otro y van viniendo, ellos se mueven por confianza (Rossi \& Caruso, M.I., 2014).

Como dice Moser (2001), es precisamente el repliegue de la estructura de interacción entre iguales lo que mejoraría la reproducción de la clase y la movilidad intra-estrato. (Filgueira, 2001, p. 39). De este modo, es posible asegurar la no contaminación del gusto aristócrata en manos de nuevos ricos, el potencial despliegue de estas estrategias es lo que permite la diferenciación del consumo y el ámbito del lujo aristócrata, manteniéndolo a distancia del lujo ostentoso, y discriminando ricos estructurales de nuevos ricos, ante la imposibilidad de una barrera de cariz meramente económico.

En cuanto a los vendedores, su posición ambigua como poseedores de un saber que va más allá de los alcances de su clase se asemeja a la posición de la servidumbre de las elites. Estos deben renunciar, o al menos suspender mientras dure el servicio, su expresión de clase, adoptando los modos y normas protocolares de aquel a quien sirven. Es posible, incluso, que se conviertan en consumidores del producto que venden, el cual sin estar a ellos destinado se les revela asequible a partir de ciertos descuentos a los que acceden en su calidad de empleados. La apariencia se vuelve, en este caso, una herramienta de trabajo que debe 
ser aprendida e internalizada, para aparentar "naturalmente" una clase y unos modos de proceder que no son los propios.

Este ensayo no es concluyente, sin embargo, gracias a él hemos podido delimitar un espacio de socialización en el que actúan dos actores, vendedor y cliente, interacción mediada por un objeto, el producto que encarna y debe proyectar los valores de una marca, actualizando en esa relación el concepto de lujo tradicional vinculado a las elites aristocráticas locales e internacionales. Nos ha permitido además delinear las preguntas con las que regresaremos al trabajo etnográfico, con el objetivo de indagar cuáles son las trayectorias de aprendizaje de los vendedores, los obstáculos que deben sortear en ese pasaje interclase y los modos en que ellos mismos perciben y reflexionan sobre sus experiencias de liminaridad. Averiguar hasta dónde esa apropiación extraña a su clase es internalizada en los vendedores de lujo tradicional provenientes de sectores medios y populares es hoy una pregunta pendiente, que esperamos responder al lector en trabajos ulteriores.

\section{Lista de referencia bibliográficas}

Barber, B. (1991). Clase y sistemas de socialización. Madrid: Fondo de Cultura Económica. Benza, G. y Heredia, M. (2012). La desigualdad desde arriba: ejercicio de reconstrucción de las posiciones sociales más altas en Buenos Aires. Buenos Aires, Argentina: En Actas VII Jornadas de Sociología de la Universidad Nacional de La Plata.

Bourdieu, P. (1999). La distinción. Criterios y bases sociales del gusto. Madrid: Taurus.

Boltanski, L. (2002). Pruebas de fuerza y pruebas legitimas. Madrid: Editorial Akal.

Filgueira, C. (2001). La actualidad de viejas temáticas, sobre los estudios de clase, estratificación y movilidad social en América Latina. Chile: Cepal

Heredia, M. (2005). La sociología en las alturas. Aproximaciones al estudio de las clases/elites dominantes en la Argentina. Buenos Aires, Argentina: Apuntes de investigación del CECYP.

Heredia, M. (2011). Ricos estructurales y nuevos ricos en Buenos Aires: primeras pistas sobre la reproducción y la recomposición de las clases altas. Buenos Aires, Argentina: Conicet

Heredia, M. (2012). ¿La formación de quién? Reflexiones sobre la teoría de Bourdieu y el estudio de las elites en la Argentina actual. La formación de las elites en la Argentina. Nuevas investigaciones y desafíos contemporáneos. Buenos Aires, Argentina: Manantial-FLACSO.

Heredia, M. (2013). Más allá de la heterogeneidad: los desafíos de analizar la estructura social en la Argentina contemporánea. Buenos Aires, Argentina: Instituto de Investigaciones Gino Germani.

Heredia, M. (2013). Notables, dueños, patrones y ricos: sobre los desafíos teórico-metodológicos de delimitar a las clases altas en la Argentina actual. Buenos Aires, Argentina: R.A.S.

Abstract: This essay proposes to investigate the circulating normalization vectors for the care of the elite client. For this, the incidence of appearance clothing, physical appearance 
and ways of proceeding in the employability in the segment of traditional luxury buying and selling will be evaluated from the study of a historic and prestigious home of leather goods, clothing and saddlery in the City of Buenos Aires, linked to the Argentine landowning elite and the international aristocracy. We will analyze the interclass socialization logics, and how their internalization -or not- by people coming from the middle and / or popular sectors can result in their potential access to work in the sector of luxury products sales.

Keywords: traditional luxury - employability - appearance normalization - commercial brands - buying and selling - fashion - middle and popular sectors - elite clients - Argentina.

Resumo: Este ensaio propõe investigar os vetores de normalização circulantes para o "cuidado" do cliente de elite. Para isso, a incidência de aparência (vestuário, aparência física e formas de proceder) na empregabilidade no segmento de compra e venda de luxo tradicional será avaliada a partir do estudo de uma histórica e prestigiada casa de artigos de couro, roupas e selaria em a cidade de Buenos Aires, ligada à elite latifundiária argentina e à aristocracia internacional. Analisaremos as lógicas de socialização interclasse e como sua internalização -ou não- por pessoas oriundas dos setores médios e / ou populares pode resultar em seu potencial acesso ao trabalho no setor de vendas de produtos de luxo.

Palavras chave: luxo tradicional - empregabilidade - normalização de aparência - marcas comerciais - compra e venda - moda - setores médios e populares - clientes de elite - Argentina.

[Las traducciones de los abstracts fueron supervisadas por el autor de cada artículo] 